\title{
Numerical response of a mammalian specialist predator to multiple prey dynamics in Mediterranean farmlands
}

\author{
François Mougeot (D) 1,5 Xavier Lambin, ${ }^{2}$ Ruth Rodríguez-Pastor,,${ }^{3,4}$ Juan Romairone, ${ }^{3,4}$ and \\ JUAN-JOSÉ LUQUe-LARENA ${ }^{3,4}$ \\ ${ }^{1}$ Instituto de Investigación en Recursos Cinegéticos (IREC-CSIC-UCLM-JCCM), Ronda de Toledo 12, 13005, Ciudad Real, Spain \\ ${ }^{2}$ School of Biological Sciences, University of Aberdeen, Tillydrone Ave, Aberdeen AB24 2 TZ United Kingdom \\ ${ }^{3}$ Departamento de Ciencias Agroforestales, Escuela Técnica Superior de Ingenierías Agrarias, Universidad de Valladolid, \\ Campus La Yutera, Avenida de Madrid 44, E-34004 Palencia, Spain \\ ${ }^{4}$ Instituto Universitario de Investigación en Gestión Forestal Sostenible, Campus La Yutera, Avenida de Madrid 44, \\ E-34004 Palencia, Spain
}

Citation: Mougeot, F., X. Lambin, R. Rodríguez-Pastor, J. Romairone, and J.-J. Luque-Larena. 2019. Numerical response of a mammalian specialist predator to multiple prey dynamics in Mediterranean farmlands. Ecology 100(9):e02776. 10.1002/ecy.2776

Abstract. The study of rodent population cycles has greatly contributed, both theoretically and empirically, to our understanding of the circumstances under which predator-prey interactions destabilize populations. According to the specialist predator hypothesis, reciprocal interactions between voles and small predators that specialize on voles, such as weasels, can cause multiannual cycles. A fundamental feature of classical weasel-vole models is a long time-lag in the numerical response of the predator to variations in prey abundance: weasel abundance increases with that of voles and peaks approximately $1 \mathrm{yr}$ later. We investigated the numerical response of the common weasel (Mustela nivalis) to fluctuating abundances of common voles (Microtus arvalis) in recently colonized agrosteppes of Castilla-y-Léon, northwestern Spain, at the southern limit of the species' range. Populations of both weasels and voles exhibited multiannual cycles with a 3-yr period. Weasels responded quickly and numerically to changes in common-vole abundance, with a time lag between prey and weasel abundance that did not exceed 4 months and occurred during the breeding season, reflecting the quick conversion of prey into predator offspring and/or immigration to sites with high vole populations. We found no evidence of a sustained, high weasel abundance following vole abundance peaks. Weasel population growth rates showed spatial synchrony across study sites approximately $60 \mathrm{~km}$ apart. Weasel dynamics were more synchronized with that of common voles than with other prey species (mice or shrews). However, asynchrony within, as well as among sites, in the abundance of voles and alternative prey suggests that weasel mobility could allow them to avoid starvation during low-vole phases, precluding the emergence of prolonged time lag in the numerical response to voles. Our observations are inconsistent with the specialist predator hypothesis as currently formulated, and suggest that weasels might follow rather than cause the vole cycles in northwestern Spain. The reliance of a specialized predator on a functional group of prey such as small rodents does not necessarily lead to a long delay in the numerical response by the predator, depending on the spatial and interspecific synchrony in prey dynamics.

Key words: common vole Microtus arvalis; common weasel Mustela nivalis; mouse; population cycles; predation; regulation; seasonality; shrew; synchrony.

\section{INTRODUCTION}

Studies of the impact of predators on prey have shown that specialized predators, which use a narrow range of prey and are more efficient when foraging on their preferred prey (Terraube et al. 2011), play a key role in influencing the regular fluctuations in abundance that characterize certain species (Turchin 2003, Krebs 2013,

Manuscript received 18 October 2018; revised 19 March 2019; accepted 3 May 2019. Corresponding Editor: F. Stephen Dobson.

${ }^{5}$ E-mail: francois.mougeot@uclm.es
Krebs et al. 2017, Myers 2018). Mustelids are predators of diverse size that occupy a wide range of ecosystems and can profoundly affect the dynamics of their prey species (King and Powell 2007, Macdonald et al. 2017). The shape and size of the smallest mustelids, exemplified by the diminutive least weasels Mustela nivalis nivalis, allows them to be highly specialized rodent predators that can hunt them in their underground burrows. Their small size, however, restricts their ability to catch larger alternative prey. The study of the interactions between mustelids and voles has greatly contributed, both theoretically and empirically, to our understanding of the circumstances under which predator-prey interactions 
could lead to fluctuating population dynamics (Hanski et al. 1993, Boutin 1995, Krebs 2013, Lambin 2017).

The dependency of small mustelids on small rodent prey increases as mustelid size decreases (King and Powell 2007). Therefore, smaller mustelid predators have the potential to cause a tighter predator-prey coupling that, under certain conditions, leads to cyclic dynamics (Hanski et al. 1993, 2001, Korpimaki et al. 1994, 2005, Turchin and Hanski 1997, Krebs 2013). In Fennoscandia (northern Europe), small mustelids have been hypothesized to cause vole population cycles, with their delayed numerical response responsible for destabilizing prey populations (Korpela et al. 2014). Stoats Mustela erminea are viewed as semigeneralist predators and, by virtue of their ability to avoid starvation through prey switching, their influence is deemed less destabilizing than that of highly small-mammal-specialized least weasels (Korpimaki and Krebs 1996, Korpimaki and Norrdahl 1998, Hanski et al. 2001, Korpimaki et al. 2005). Mathematical models have shown that such predatorprey cycles can occur when there is both reciprocal feedback (i.e., the population growth rate [PGR] of the prey influences that of the predator and vice versa) and the existence of an emerging time lag due to the PGR of the predator being slower than the PGR of prey (Hanski et al. 1993, Turchin and Hanski 2001, Henttonen et al. 2017).

The potential for causing cyclic dynamics is greater when mustelids are sufficiently efficient to deplete entire small-mammal prey assemblages, subsequently causing a crash in weasel populations through starvation and/or reproductive failure. In order to do so, the predator kill rate must be sufficient for weasels to impact vole PGR. Models of small mustelid-vole cycles include a type II functional response; a "surplus killing" that may amount to $50 \%$ of the food requirements of predators (Jedrzejewska and Jedrzejewski 1989), and vole self-regulation with carrying capacities $(K)$ of up to 150 voles per ha, commensurate with values encountered in boreal forest and tundra ecosystems (Hanski et al. 1993, 2001, Turchin and Hanski 1997). The favored hypothesis to explain vole cycles in Fennoscandia invokes generalist and mobile specialist predators responding numerically to vole abundance without delay, which moderates the destabilizing influence of omnipresent least weasels along a north-south geographical gradient of decreasing cycle length (Hansson and Henttonen 1985, Bjørnstad et al. 1995, Turchin and Hanski 1997, Hanski et al. 2001).

Virtually all interpretations of empirical data on vole cycles from Fennoscandia emphasize the importance of a delayed numerical response of weasel abundance with a $\geq 1$-yr lag. For instance, Hansen et al. (1999) interpreted the 2-yr delayed density dependence in time series of vole abundance from northern Finnish Lapland, which is particularly evident in winter, as indicative that the delayed effect of the weasels must be presaged by a high spring density of rodents. This leads to a weasel population explosion the following spring/summer, and continues having a major effect on the rodents in the second winter thereafter. Also in Finland, Sundell et al. (2013) and Korpela et al. (2014) found some evidence for the abundance of weasels, but not of stoats, to lag behind vole abundance using indices of mustelid abundance derived from snow tracking. The bulk of support for causally linked mustelid-prey cycles centers on the delayed numerical responses of either least weasels causing vole cycles in Fennoscandia (Korpela et al. 2014), or stoats causing lemming cycles in Greenland (Gilg et al. 2003).

However, the evidence from weasel studies in other ecosystems where similar vole cycles are now well documented (e.g., Poland, United Kingdom), indicates that the key time-lag condition is not always met (Jedrzejewski et al. 1995, Lambin et al. 2000, 2006, Graham and Lambin 2002, Zub et al. 2008). The absence of empirical evidence of a long time lag would reject the specialist predator hypothesis as currently formulated as an explanation for vole cycles in other ecosystems where weasels are also ubiquitous, such as Fennoscandia (Lambin 2017). In productive farmland ecosystems where common-vole cycles occur, such as in continental and temperate Europe (Jedrzejewski and Jedrzejewska 1996, Tkadlec and Stenseth 2001), vole-carrying capacities $(K)$ are likely higher than in Fennoscandia, and avian predators are also abundant. Because small mustelids are territorial (Erlinge 1974, King and Powell 2007), their numerical response may be limited by territorial behavior (see Turchin 2003) rather than by predator-prey ratios, thus making predator saturation more likely when $K$ is high. Consequently, weasel numbers have been suggested to mirror fluctuations in rodent numbers that are actually determined by other factors, and as such the role of weasels would not be sufficient to destabilize vole populations in these ecosystems (Lambin 2017).

The enduring controversy surrounding the weaselvole cycles illustrates the difficulties of drawing inference on causation from correlative data, and of performing experiments at appropriate scales with small mustelids in wild populations. Studying and conducting experiments with small mustelids, like weasels, is challenging because they are secretive, highly mobile, and difficult to trap (Klemola et al. 1997, 2000, Korpimaki and Norrdahl 1998, Graham and Lambin 2002, Lambin 2017). One way to overcome such limitations would be to accumulate nonexperimental studies in different areas where predators and prey share the same life history, in order to develop a general understanding of predator-prey interactions involving rodents.

Some processes invoked as possibly modifying weasel-vole reciprocal dynamic interactions (e.g., generalist predators, snow cover, availability of refuges, prey diversity and asynchrony, diet shifts) vary on a broad geographical scale, and are expected to have stabilizing effects on prey dynamics. For instance, generalist mammalian or avian predators may compensate for the 
destabilizing impact of small mustelids on voles or may act as intraguild predators that modify or cancel the numerical response of small mustelids to prey abundance (Erlinge 1974, Erlinge et al. 1984, Turchin and Hanski 1997, Korpimaki and Norrdahl 1998, Oksanen et al. 2001, Lambin 2017). The impact of generalist predators will depend on the ability of small mustelids to find protection from those predators in safe habitats (Hansson and Henttonen 1985, Oksanen et al. 2001, Zub et al. 2008). There is a conspicuous difference between the northern boreal ecosystems, where only weasels can safely continue to hunt rodents under the snow all winter (Hansson and Henttonen 1985, Oksanen et al. 2001), and the temperate Mediterranean ecosystems, where weasels could have much less protection from intraguild predation and be merely one component of a broader community of vole predators. In addition, spatial asynchrony in density of a preferred prey or a broader dietary spectrum could allow the larger subspecies of weasels and stoats to switch between asynchronous alternative prey, thereby modifying their numerical response to cyclic voles (Lambin 2017).

We took advantage of the recent appearance of largescale, recurrent population outbreaks of common voles Microtus arvalis in southern Europe (Luque-Larena et al. 2013), to study the dynamic interactions between common weasel Mustela nivalis vulgaris and its smallmammal prey within a new ecological context. In Castilla-y-León, northwestern Spain, the common vole recently invaded about 5 million hectares of previously unoccupied farmland habitat following increases in the extent of irrigated crops and alfalfas in which voles can thrive (Luque-Larena et al. 2013, 2018, Jareño et al. 2015). Since the colonization, recurrent large-scale population outbreaks of common voles have occurred in the region. This offers an unprecedented opportunity to investigate how native common weasels respond to abundance fluctuations of voles and other small-mammal prey at the southern limit of the common-vole distribution range. Using $9 \mathrm{yr}$ of continuous seasonal monitoring (every 4 months) with a constant trapping effort in three study sites, we tested whether the numerical response of weasels to prey abundance occurred with a 1-yr time lag. We also considered whether the abundances of small-mammal prey (voles, mice, and shrews) were synchronous within and among sites. The presence of prey asynchrony could influence the numerical response of weasels.

\section{Methods}

\section{Study areas and species}

We studied the common weasel and its small mammal prey community in "Tierra de Campos," Castilla-y-León region, NW Spain (Fig. 1). The landscape is dominated by agricultural fields with little tree cover and the climate is continental-Mediterranean (Paz et al. 2013, Jareño et al. 2015, Rodriguez-Pastor et al. 2016). Study sites (about $20 \mathrm{~km}^{2}$ each) were located in the provinces of Palencia $\left(42^{\circ} 02^{\prime} \mathrm{N} ; 4^{\circ} 68^{\prime} \mathrm{W}\right.$; hereafter Site 1), Valladolid $\left(41^{\circ} 61^{\prime} \mathrm{N} ; 5^{\circ} 24^{\prime} \mathrm{W}\right.$; Site 2$)$, and Zamora $\left(41^{\circ} 87^{\prime} \mathrm{N} ; 5^{\circ} 61^{\prime}\right.$ W; Site 3), and were 55-80 km apart from each other (Rodriguez-Pastor et al. 2016).

The small-mammal community is typically composed of common voles, two mouse species (wood mouse Apodemus sylvaticus and Algerian mouse Mus spretus), and one shrew (greater white-toothed shrew Crocidura russula). The common vole is a small herbivore traditionally found in grasslands and meadows of the peripheral mountains of Castilla-y-León and in the Pyrenees. In the late 1980s, common voles colonized the lowland farmland habitats of Castilla-y-León, resulting in the appearance of regional-scale common-vole outbreaks in farmland that have had profound ecological and socioeconomic impacts (Luque-Larena et al. 2013, 2015, 2018).

In the Iberian Peninsula, the common weasel is widely distributed and occupies a wide range of habitats where small-mammal prey occur. It is larger and has a broader diet than the least weasel of northern Europe (Blanco 1998, King and Powell 2007, Palazón 2017). Dietary studies in the Iberian weasels highlight the dominance of small-rodent prey, in particular Apodemus and Mus mice, as well as Microtus voles when available (Palazón 2017). When small mammals are scarce, common weasels can also feed on small birds, amphibians, small reptiles, invertebrates, or even fruit. Larger males can catch rabbits, and smaller females hunt mostly burrowing rodents (Blanco 1998, Palazón 2017).

\section{Small mammal trapping and abundance estimates}

From July 2009 until November 2017, we sampled small mammals using live trapping conducted in each of the three study sites every 4 months (in March, July, and November). For simplicity, we use the word "season" for our 4-month time intervals in between the three annual samples (March, July, and November would correspond to the spring, summer, and autumn samples, respectively). Overall, we obtained data for 26 consecutive seasonal samples in each study site, covering a period of 9 yr.

During each season, we sampled the dominant habitats of the farming landscape: cereal fields, alfalfa fields, and fallows (uncultivated plots or set-asides covered by natural or seminatural vegetation; Rodriguez-Pastor et al. 2016). For each season, we selected 12 fields by crop type (four cereals, four alfalfas, and four fallows) in each study site. Within each field (sample unit), we set up 35 live traps $(8 \times 9 \times 23 \mathrm{~cm}$; LFAHD Sherman $)$ spaced every $2 \mathrm{~m}$ and forming a T shape: 10 traps were placed along a $20-\mathrm{m}$ transect line in the field margin, and 25 traps were placed along a 50 -m transect line perpendicular to the field margin and oriented toward the field center (see Rodriguez-Pastor et al. 2016). Each trap 

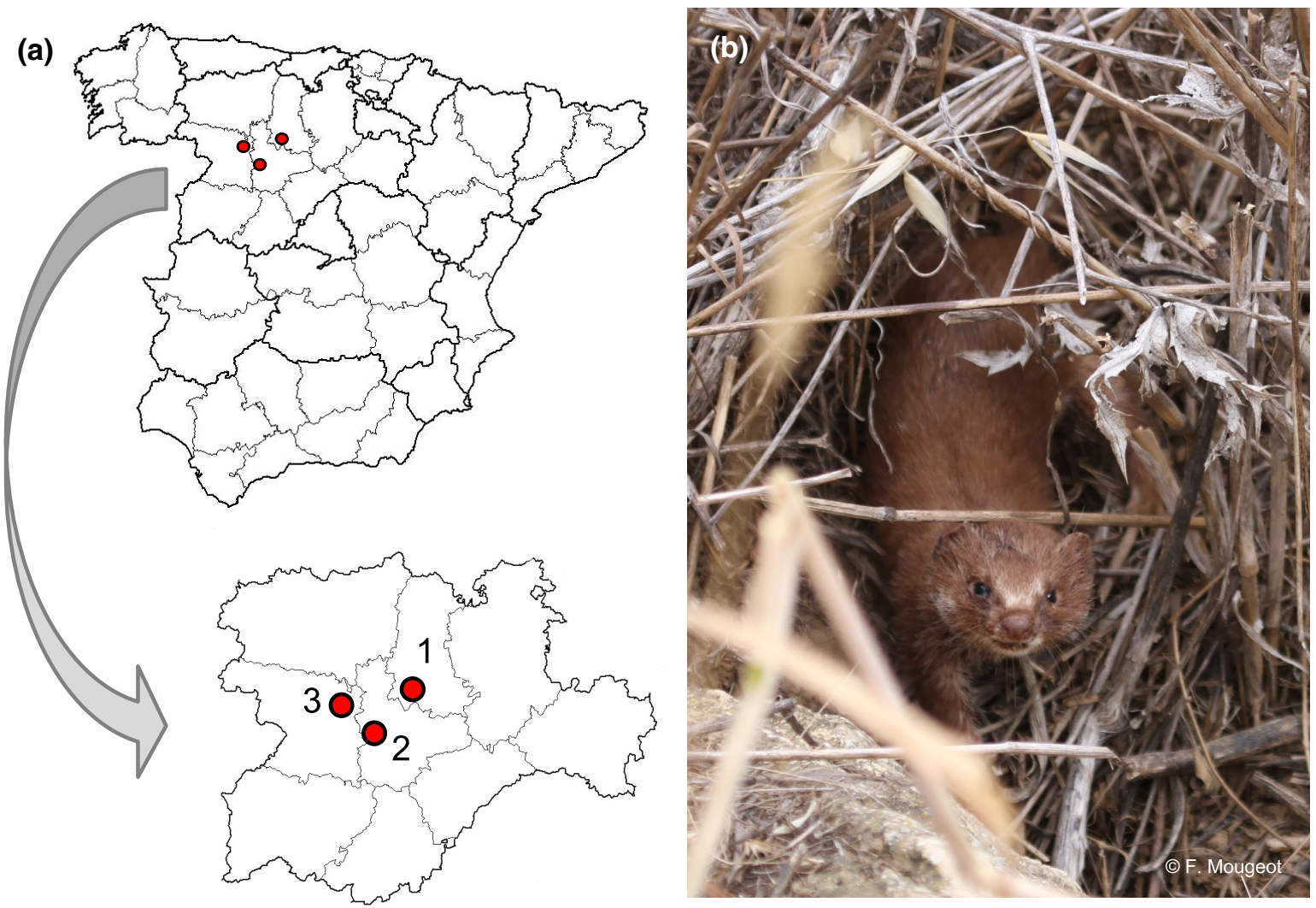

FIG. 1. Location of the three study sites in northwest Spain. (a) Trapping was conducted in 2009-2017 in three $20-\mathrm{km}^{2}$ sites (red dots) 55-80 km apart located in the provinces of (1) Palencia, (2) Valladolid, and (3) Zamora. (b) Photo of a common weasel from NW Spain (F. Mougeot, Palencia 2014).

was baited with apple or carrot, which provide both food and water for trapped rodents. When the temperatures were low (autumn and winter), hydrophobic cotton was provided inside traps to increase survival (see Romairone et al. 2018). Traps were set up in the morning, inspected after $24 \mathrm{~h}$, and subsequently removed. We recorded for each capture the trap location and species trapped. Most small-mammal captures were of common voles $(50.4 \%)$, followed by wood mice $(25.0 \%)$, Algerian mice $(16.4 \%)$, and white-toothed shrews (6.3\%; see also Rodriguez-Pastor et al. 2016). During a given season, trapping was performed sequentially in the three sites using the same set of traps (420 traps set for $24 \mathrm{~h}$ in one site, retrieved and set in the next site, and so on).

Sherman traps that captured weasels kept the pungent scent of the mustelid and may be subsequently avoided by prey (Gorman 1984). These were always taken back to the lab and thoroughly washed with soap and water, rinsed and dried before being reused for captures. The traps that captured other small mammals (rodents, shrews) were simply cleaned with dry paper (to remove feces and urine) and left to completely air dry before the next trapping session. Weasels entered Sherman traps previously used by prey (i.e., with residual odors) significantly more often than they entered unused, brand new, odorless traps (F. Mougeot and J.-J. Luque-Larena, unpublished data). The traps used for monitoring small mammals were tainted by a mixture of old dry odors of rodents and shrews, which likely attracted weasels. To evaluate whether this could bias estimates of weasel capture rate in a given site and season, we tested for a possible effect of the order in which the sites were trapped on weasel capture rate. We found no influence of trapping order (Appendix S1) and therefore had no evidence that the residual odors left by recently captured prey influenced our weasel capture rate index.

We captured a total of 107 common weasels. Whenever possible (some individuals escaped during trap inspection or handling), common weasels were sexed and aged before being released on site. We also noted whether female weasels had apparent signs of reproduction, such as being visibly pregnant or lactating. Weasels were categorized as young or old (i.e., less than $1 \mathrm{yr}$ old, or older) based on the sharpness of their canine teeth: young have very sharp white canine teeth that wear off and become greyish, rounded, or broken in older weasels (King and Powell 2007).

Because the density of traps (traps per unit area) and trapping effort did not vary between study sites or over time, our trapping indices from different sites and times 
were comparable. We used these trapping data to derive several capture-rate estimates, used as proxies of speciesspecific abundances at two different spatial scales:

1) At the site level, we calculated an abundance index for each species and season, as the average capture rate for the 12 sampled fields (with a trapping effort of $12 \times 35$ traps/field $=420$ trap days per season) and expressed as number of captures/100 traps/24 h. Traps that were closed but empty or that were occasionally stolen or destroyed during farming activities were excluded from calculations. Previous studies on small mammals suggest that measures of relative abundance provide patterns of population trends proportional to those derived from estimates of absolute abundance (Hopkins and Kennedy 2004). For common voles, this abundance index has been shown to provide an accurate measure of density (Jareño et al. 2015). We applied the same density index to the other study prey species. At site level, we also calculated species-specific population growth rates (PGR) between consecutive seasonal samples as follows: $\mathrm{PGR}_{t}$ to $\mathrm{PGR}_{t+1}=\log \left(\right.$ abundance $\left._{t+1}\right)-\log$ (abundance $_{t}$ ).

2) At the regional level, we calculated an abundance index for each species that was the overall average for the three study sites at a given time (with a trapping effort of 1,260 trap days), hereafter referred to as regional abundance estimates.

\section{Statistical analyses}

We used R v3.4.3 for all statistical analyses (R Core Team 2014). Generalized linear mixed models (GLMMs) were used to investigate the associations between weasel capture rate and current (time $t$ ) and previous abundance (at times $t-4$ months, $t-8$ months and $t-$ 12 months) of small mammals depending on season. A first set of models considered the current and previous abundances of all small mammals (vole + mice + shrew), and a second set of models considered those of voles, mice (wood mouse and Algerian mouse), and shrews separately. Explanatory variables were sequentially removed from initial models, starting with interactions, using a backward selection procedure (drop1 function). GLMMs were also used to test whether small-mammal PGRs differed between seasons, including "site" as a fixed effect and "year" as a random effect. Dependent variables (weasel capture rate, log-transformed; PGRs) were entered into models that used a normal error distribution. A normal distribution of residuals was achieved, and we provided pseudo- $R^{2}$ values (r.squaredGLMM function) as measures of goodness-of-fit of models. We used Pearson correlations to investigate within- and between-site synchrony, testing for associations between the PGRs calculated for each seasonal interval, species, and site. Finally, we used autocorrelation (acf function) and cross-correlation (ccf function) analyses to look for a multiannual periodicity, and for coupling of weasel and prey PGRs at the regional level.

\section{RESULtS}

\section{Sex ratio, age ratio, and reproductive status of captured weasels}

Our results suggested a seasonal peak in weasel reproduction during March-July, though reproduction occurred year round. On average, capture rates were twofold higher during July $(0.41 \pm 0.11 ; n=27)$ than during November $(0.19 \pm 0.06, n=27)$ or March $(0.18 \pm 0.06$, $n=24)$. Of 71 captured weasels with known sex, $46.5 \%$ were females. We found no evidence of significant differences in capture sex ratio among seasons $\left(\chi^{2}=4.71\right.$; $\mathrm{df}=2 ; P=0.09)$. The proportion of captured females was $61.9 \%$ in March $(n=21), 30.8 \%$ in July $(n=26)$, and $50 \%$ in November $n=24)$. The proportion of captured young was $30 \%$ in March $(n=10), 16.7 \%$ in July $(n=18)$, and $38.9 \%$ in November $(n=18)$. In July, $37.5 \%$ of eight captured females were in late pregnancy or lactating. Fewer females showed signs of reproduction in November $(16.7 \%, n=12)$ or March $(8.3 \%, n=12)$, though there were juveniles and lactating females in all seasons, indicative of an extended breeding period.

\section{Weasel numerical response}

Common vole and weasel capture rates varied more than 20-fold among years, with three marked peaks (2011, 2014, and 2017; Fig. 2a, b). We first investigated the numerical response of common weasels to the abundance of all small-mammal prey at different time lags (none, 4, 8, and 12 months before) and then to that of specific prey species. For the latter, we pooled the functionally similar wood mouse and Algerian mouse, considering an overall mouse abundance, because of collinearity issues (both mice species showed similar seasonal dynamics and marked within-site synchrony; see the following). Weasel capture rate in a given site and season was significantly explained by current small-mammal abundance (positive) and previous small-mammal abundance (4 months before) in interaction with season (Table 1; pseudo- $R^{2}=0.53$ ). No significant associations were found for other time lags (8 or 12 months before), irrespective of season. When considering the abundances of voles, mice, and shrews separately, we obtained final models that were very similar but included only the current and previous ( $t-4$ months) abundance of common voles, the latter in interaction with season (Table 1; pseudo- $R^{2}=0.54$ ). The current or previous abundances of mice or shrews did not explain weasel capture rate, irrespective of season, and were dropped during model selection (all $P>0.10$ ). In all seasons, weasel capture rate increased with the current abundance of common voles (Fig. 3a). In addition, weasel capture rate increased with common-vole abundance 4 months before, and this 
increase was steeper during July than during March or November (Fig. 3b, Table 1).

\section{Seasonal population growth rates}

Common-weasel PGR varied seasonally (mixed effect model with year as a random effect and site as a fixed effect: $\chi^{2}=9.57 ; \mathrm{df}=2 ; P<0.01 ;$ pseudo- $R^{2}=0.12$ ), with a higher PGR for March-July than for JulyNovember, and an intermediate PGR for NovemberMarch (Fig. 4a). PGRs of the small-mammal prey also varied strongly with season $\left(\chi^{2}=15.78,32.83,74.36\right.$, and 39.72; all $\mathrm{df}=2$; all $P<0.001$; pseudo- $R^{2}=0.15$, $0.29,0.50$, and 0.35 for common vole, wood mouse,
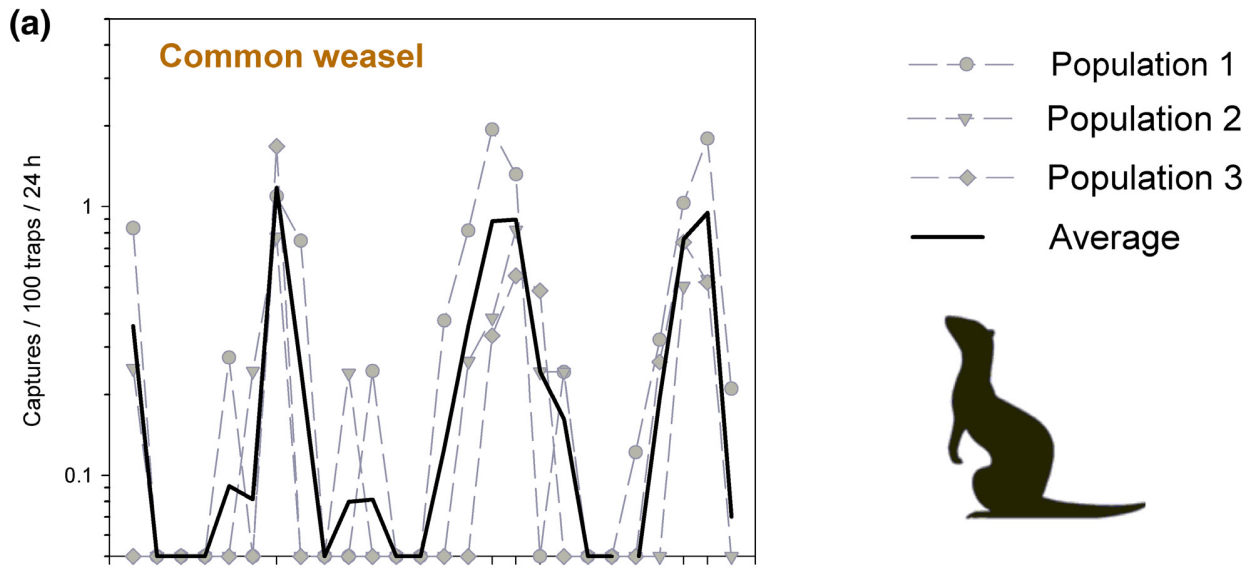

- Average
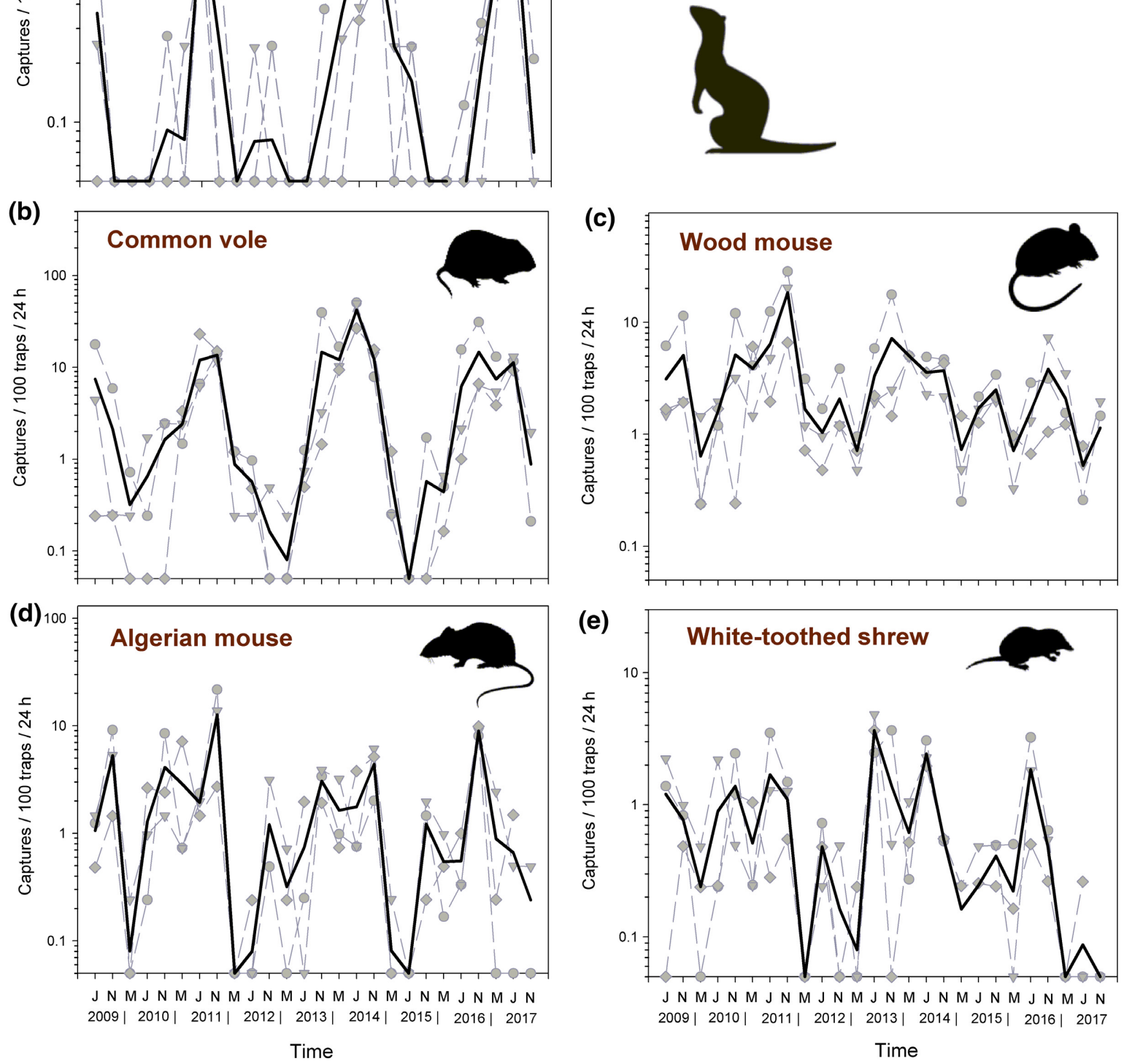

FIG. 2. Temporal variation in the capture rate (log-scale) of (a) common weasels and their main small-mammal prey: (b) common vole, (c) wood mouse, (d) Algerian mouse, (e) greater white-toothed shrew. The dotted grey lines and different symbols show data for each study site and the thicker black line the regional average at a given time. 
TABLE 1. Numerical response of weasels to current and previous small mammal abundances. Results of the general linear mixed models testing for associations between weasel capture rate and current/previous prey abundances.

\begin{tabular}{|c|c|c|c|c|c|}
\hline Dependent variable & Final model & $\chi^{2}$ & $\mathrm{df}$ & $P$ value & Estimates \\
\hline \multirow[t]{5}{*}{ (1) Weasels $t^{\dagger}$} & Intercept & & & & $-0.306 \pm 0.193$ \\
\hline & Season & 0.43 & 2,59 & 0.976 & $\begin{array}{l}-0.146 \pm 0.228 \text { (July) } \\
-0.071 \pm 0.243 \text { (November) }\end{array}$ \\
\hline & Small mammal $\mathrm{Ab}_{t}$ & 3.76 & 1,59 & 0.049 & $+0.085 \pm 0.445$ \\
\hline & Small mammal $\mathrm{Ab}_{t-4}$ & 3.96 & 1,59 & 0.046 & $+0.137 \pm 0.069$ \\
\hline & Season $\times$ small mammal $\mathrm{Ab}_{t-4}$ & 10.45 & 2,59 & 0.005 & $\begin{array}{l}+0.302 \pm 0.104 \text { (Jul.) } \\
+0.024 \pm 0.094 \text { (November) }\end{array}$ \\
\hline \multirow[t]{5}{*}{ (2) Weasels $t^{\dagger}$} & Intercept & & & & $-0.102 \pm 0.103$ \\
\hline & Season & 0.05 & 2,59 & 0.976 & $\begin{array}{l}+0.030 \pm 0.137 \text { (Jul.) } \\
+0.014 \pm 0.136 \text { (November) }\end{array}$ \\
\hline & Common vole $\mathrm{Ab}_{t}$ & 6.20 & 1,59 & 0.013 & $+0.108 \pm 0.043$ \\
\hline & Common vole $\mathrm{Ab}_{t-4}$ & 4.83 & 1,59 & 0.028 & $+0.122 \pm 0.056$ \\
\hline & Season $\times$ common vole $\mathrm{Ab}_{t-4}$ & 8.41 & 2,59 & 0.015 & $\begin{array}{l}+0.227 \pm 0.098 \text { (Jul.) } \\
-0.035 \pm 0.076 \text { (November) }\end{array}$ \\
\hline
\end{tabular}

$\dagger$ Dependent variable $=$ weasel capture rate $($ captures/100 traps/24 h) at site level. Models included Year as a random effect. Initial models included the following explanatory variables: Site (three-level factor), Season (three-level factor), current and previous prey abundances (at times $t-4$ months, $t-8$ months and $t-12$ months) and their interactions with Season. These were sequentially removed from initial models, starting with interactions, using a backward selection procedure (dropl function in R). The first model selection (1) considered the abundances of all small mammals (vole + mice + shrew), and the second model selection (2) considered the abundances of voles, mice (wood mouse and Algerian mouse) and shrew separately. All abundance data included as explanatory variables were log-transformed.
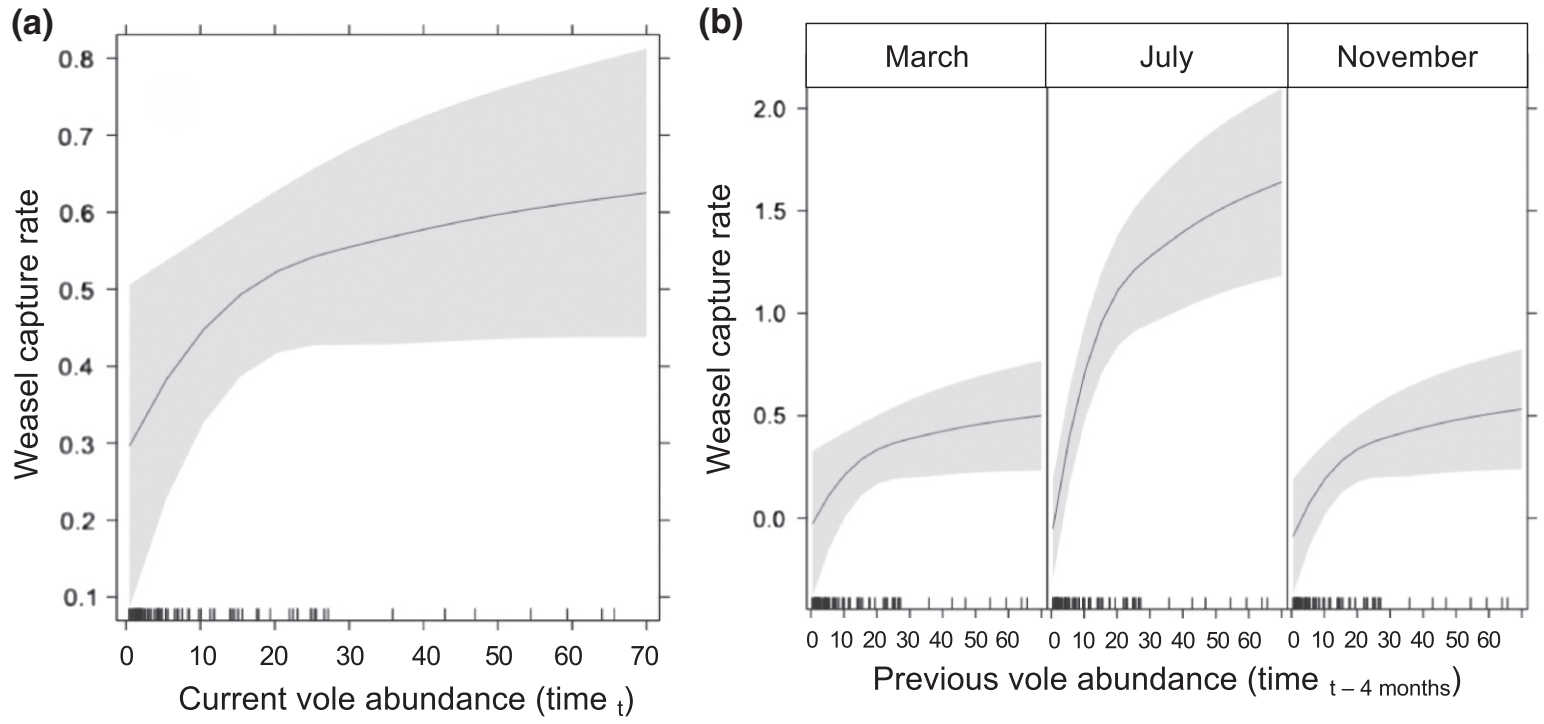

FIG. 3. Numerical response of common weasels to current and previous common-vole abundance. Relationship between weasel capture rate (captures/100 traps/24 h) and (a) current vole abundance (captures/100 traps/24 h) and (b) previous vole abundance (4 months earlier) and season. Weasels responded to current vole abundance in all seasons and more strongly to previous spring (March) vole abundance during summer (July).

Algerian mouse and shrew, respectively), with some differences between species. The PGR of common voles was greatest for March-July, as for weasels, and lowest for November-March (Fig. 4b). Both mouse species showed moderate increases for March-July followed by marked increases for July-November and declines for
November-March (Fig. 4c, d). The shrew populations only increased for March-July and declined in other time periods (Fig. 4e).

Common-weasel PGR was significantly positively associated with contemporary common-vole PGR $\left(\chi^{2}=\right.$ 22.95; $\mathrm{df}=1 ; P<0.001 ;$ slope $\pm \mathrm{SE}:+0.489 \pm 0.114$; 
(a)

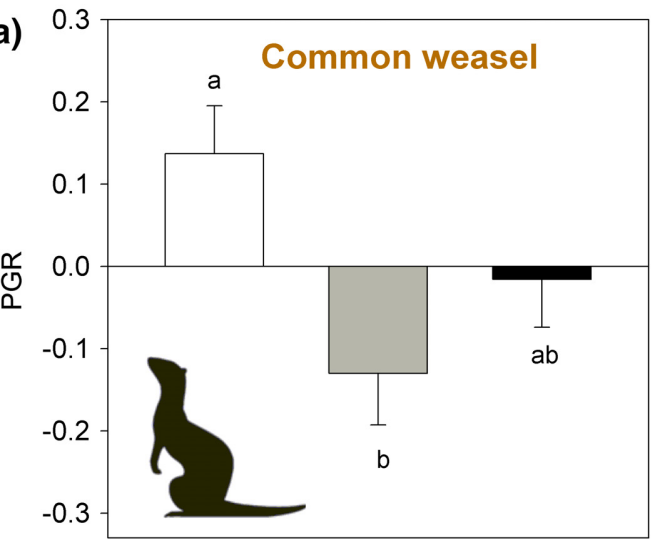

(c)

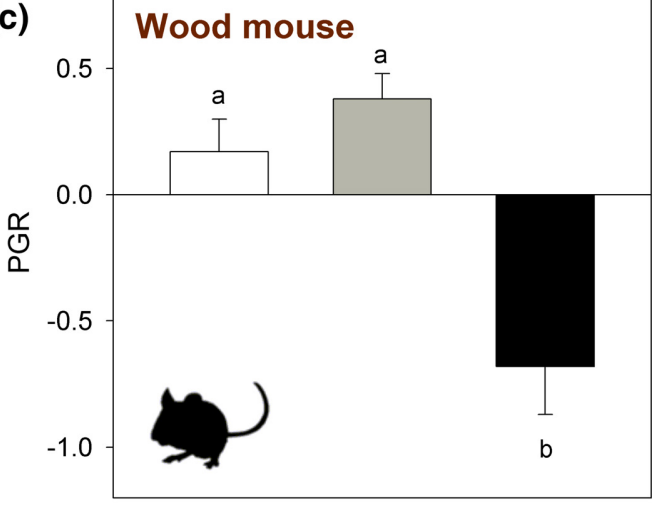

Time period

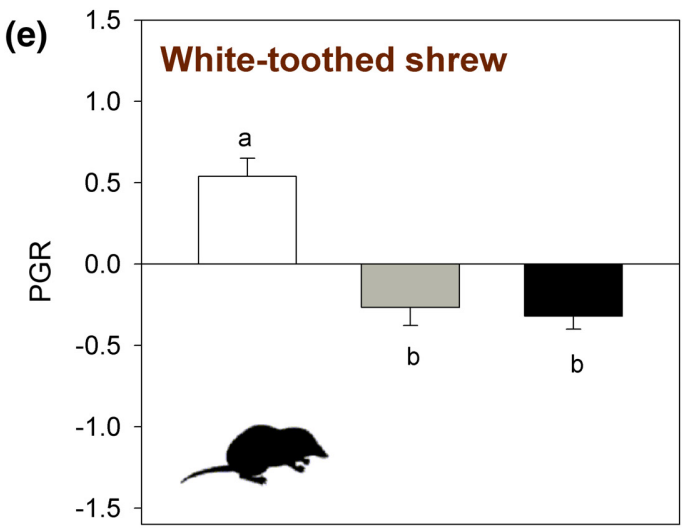

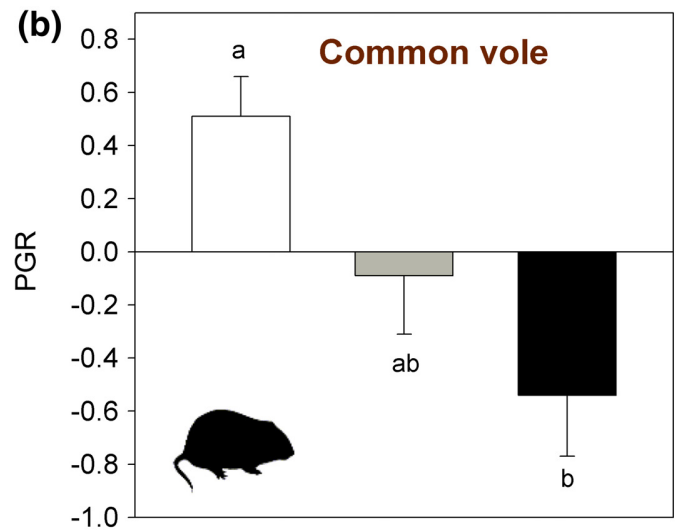

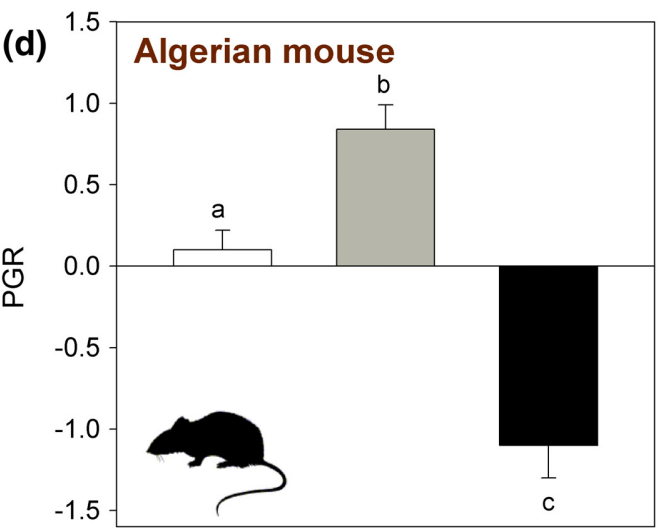

Time period

Time periods:

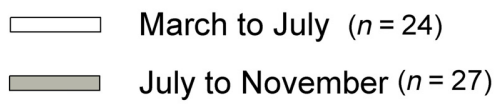

November to March $(n=24)$

Time period

FIG. 4. Seasonal variation in the population growth rate (PGR, mean \pm SE) of (a) common weasels and their small mammal prey: (b) common vole, (c) wood mouse, (d) Algerian mouse, (e) greater white-toothed shrew. For pairwise comparisons, different letters indicate significant differences $(P<0.05)$ between time periods (Tukey's tests). Sample sizes refer to number of time periods and sites included in the analyses.

pseudo- $R^{2}=0.30$ ) but not related to either mouse PGR $\left(\chi^{2}=1.17 ; \mathrm{df}=1 ; P=0.28\right)$ or shrew PGR $\left(\chi^{2}=2.23\right.$; $\mathrm{df}=1 ; P=0.13$ ). Previous vole PGR (during the previous $4-8$ or $8-12$ months) did not significantly explain weasel PGR $\left(\chi^{2}=2.25 ; \quad P=0.134\right.$ and $\chi^{2}=0.166$; $P=0.684$, respectively).
Synchrony

Weasel PGR was significantly spatially correlated between sites $55-80 \mathrm{~km}$ apart (Pearson correlation coefficients of $0.46,0.61$, and 0.71 ; Table 2), indicating some level of synchrony between sites. This was also the case 
for the common-vole PGR $(0.60<r<0.80)$ and the Algerian mouse PGR $(0.48<r<0.84)$. For the wood mouse and the greater white-toothed shrew, not all pairwise comparisons were significant (Table 2), indicating a lower level of synchrony among sites. Within sites, we found a stronger cross-correlation between weasel PGR and common-vole PGR than between weasel PGR and other prey PGRs (Table 3). We also found a strong association between the PGR of the two mouse species (Algerian and wood mouse) in the three study sites (Table 3).

\section{Periodicity}

At regional level (average values from the three study sites), weasel capture rate showed three marked annual peaks, in 2011, 2014, and 2017 (Fig. 3a). An autocorrelation analysis for the regional weasel PGR revealed a positive autocorrelation for a time lag of 36 months $(r=0.41 ; P<0.05)$. In addition, there was a significant

TABLE 2. Predator and prey synchrony between sites.

\begin{tabular}{|c|c|c|c|}
\hline Species & Sites & Site 1 & Site 2 \\
\hline \multirow[t]{2}{*}{ Common weasel } & Site 2 & $0.61 * * *$ & \\
\hline & Site 3 & $0.46^{* *}$ & $0.71 * * *$ \\
\hline \multirow[t]{2}{*}{ Common vole } & Site 2 & $0.72 * * * *$ & \\
\hline & Site 3 & $0.60 * * *$ & $0.80 * * * *$ \\
\hline \multirow[t]{2}{*}{ Wood mouse } & Site 2 & $0.68 * * * *$ & \\
\hline & Site 3 & 0.20 & $0.39 *$ \\
\hline \multirow[t]{2}{*}{ Algerian mouse } & Site 2 & $0.84 * * * *$ & \\
\hline & Site 3 & $0.54 * * *$ & $0.48 * *$ \\
\hline \multirow[t]{2}{*}{ White-toothed shrew } & Site 2 & $0.49 * *$ & \\
\hline & Site 3 & $0.36^{*}$ & $0.63^{* * * *}$ \\
\hline
\end{tabular}

Note: Correlations between sites for the population growth rates of small mammals (Pearson correlation coefficients; all $n=26$; significant correlations are highlighted in bold).

${ }^{*} 0.05<P<0.10 ; * * P<0.05 ; * * * P<0.01 ; * * * P<0.001$. cross-correlation between weasel PGR and commonvole PGR with no time lag, as well as a time-lag of 36 months (Fig. 5), consistent with synchronized coupled multiannual dynamics between weasels and voles with a 3-yr period. Autocorrelation analyses conducted on the PGR of prey species provided evidence for multiannual cycles with a period of 36 months for the common vole, and evidence for annual seasonal dynamics (autocorrelations at time lags of 12 months) with no multiannual periodicity for mice (Algerian and wood mice combined) or greater white-toothed shrew (Fig. 6).

\section{Discussion}

\section{Common-vole population cycles at the southernmost part of their range}

The fluctuations in the abundance of common voles observed in NW Spain during 2009-2017 were consistent with a 3-yr cycle (Figs. 2 and 5), providing a southernmost context to scrutinize vole cycles and the role of weasels. Although a longer time series and more spatial replicates would be desirable, ours is the first statistical evidence for regular common-vole cycles to occur at the southernmost limit of their distribution range. The pattern of fluctuation is similar to that of the farmlands of western France, where common voles also fluctuate with a 3-yr period (Lambin et al. 2006, Barraquand et al. 2014). Unlike common voles, the other weasel mammalian prey (mice and shrews) showed annual, seasonal dynamics, with no evidence of interannual periodicity (Figs. 2 and 6). Wood mouse and Algerian mouse abundances typically showed moderate increases from March to July and larger increases from July to November (autumn peak), whereas white-toothed shrew abundance mostly increased from March to July (summer peak; Fig. 4). Thus, weasels in NW Spain have access to

TABLE 3. Predator and prey synchrony within sites.

\begin{tabular}{|c|c|c|c|c|c|}
\hline Sites & Species & Common vole & Algerian mouse & Wood mouse & White-toothed shrew \\
\hline \multirow[t]{4}{*}{ Site 1} & Common weasel & $0.60 * * *$ & 0.17 & 0.26 & 0.36 \\
\hline & Common vole & & $0.53 * * *$ & $0.57 * * *$ & $0.61 * * *$ \\
\hline & Algerian mouse & & & $0.80 * * * *$ & 0.34 \\
\hline & Wood mouse & & & & $0.58 * * *$ \\
\hline \multirow[t]{4}{*}{ Site 2} & Common weasel & $0.38^{*}$ & -0.16 & -0.20 & 0.03 \\
\hline & Common vole & & $0.35^{*}$ & $0.40^{* *}$ & 0.33 \\
\hline & Algerian mouse & & & $0.72 * * * *$ & -0.10 \\
\hline & Wood mouse & & & & 0.33 \\
\hline \multirow[t]{4}{*}{ Site 3} & Common weasel & $0.45^{* *}$ & -0.17 & -0.26 & -0.14 \\
\hline & Common vole & & $0.50 * *$ & $0.44 * *$ & 0.18 \\
\hline & Algerian mouse & & & $0.52 * * *$ & $0.34 *$ \\
\hline & Wood mouse & & & & 0.24 \\
\hline
\end{tabular}

Note: Correlations within sites for the population growth rates of small mammals (Pearson correlation coefficients; all $n=26$; significant correlations are highlighted in bold).

$* 0.05<P<0.10 ; * * P<0.05 ; * * * P<0.01 ; * * * P<0.001$. 

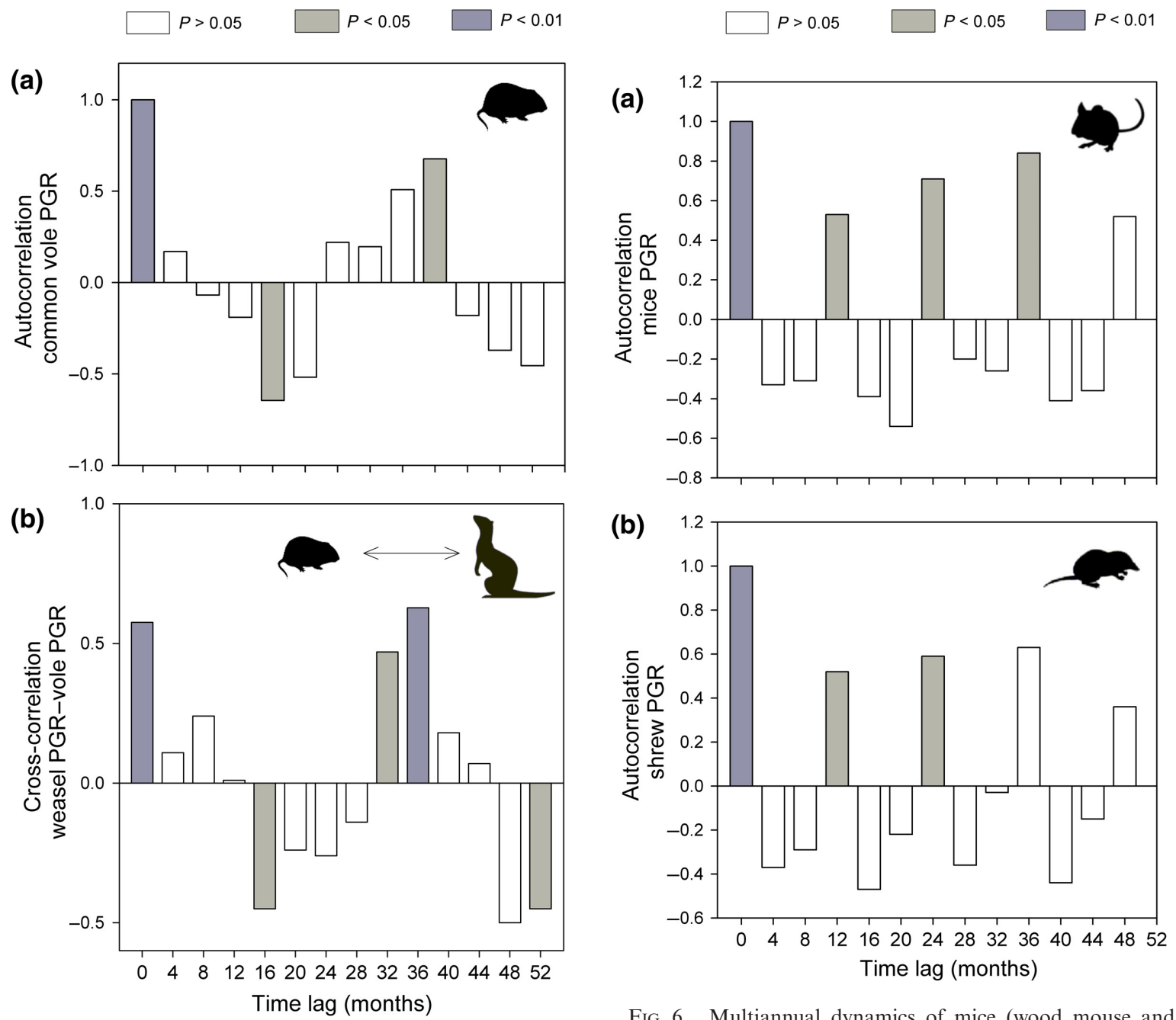

FIG. 5. Coupled multiannual dynamics of common voles and weasels. (a) Autocorrelation of the common-vole population growth rate (PGR), and (b) cross-correlation between the weasel PGR and the common-vole PGR at regional level for time lags of $0-52$ months.

alternative small-mammal prey even when the arguably more profitable vole populations were at the nadir of their 3-yr cycle.

\section{Numerical response of weasels to fluctuations in abundance of prey}

Small mustelids are hypothesized to cause vole cycles in Fennoscandia, which is often presented as a ubiquitous explanation for such fluctuations elsewhere (Henttonen et al. 2017). A key feature of classical weasel-vole cycle models is a 1-yr delay in the numerical response of weasels to prey abundance, reflecting a lower growth rate of weasels relative to their prey and the dependence of weasel reproduction and survival on prey abundance. However, accurately estimating weasel abundance is

FIG. 6. Multiannual dynamics of mice (wood mouse and Algerian mouse combined) and greater white-toothed shrew. Autocorrelation of (a) mice vole population growth rate (PGR), and (b) white-toothed shrew PGR at regional level for time lags of $0-52$ months.

extremely difficult, and thus evidence for such a delay should be regarded with caution (Lambin 2017).

Absolute estimates of mustelid density are rare (e.g., Fuller et al. 2016) and measures of absolute abundance repeated over several years even rarer. Most of what is known about small-mustelid population dynamics is derived from indices of abundance, such as harvest data, live trapping indices, footprint tunnel tracking, or snow tracks (Jedrzejewski et al. 1995, 2000, Graham 2002, King and Powell 2007, Sundell et al. 2013). Measures based on signs of activity have limitations. For instance, track indices may be higher relative to abundance when prey become scarce and predator searching effort increases, potentially yielding spurious evidence of a delayed numerical response (Lambin 2017). Our results, consisting of weasel capture rate in traps set for other small mammals with a constant trapping in each site 
over time, likely reflected both abundance and preysearching activity, and also have limitations.

Weasels were likely attracted to traps containing residual odors left by previously captured prey. All the traps used during our monitoring were soiled, that is, tainted by previously captured mammalian weasel prey (voles, mice, shrews). We never used traps soiled with weasel scent. Noteworthy, variation in our weasel trapping index in a given site and season was not explained by the order in which the sites were trapped, and thus by the amount of residual odors recently accumulated in traps (Appendix S1). Using traps that were not recently soiled did not result in a reduced weasel trapping index. This potential source of bias was unlikely to mask a longer time delay in the response of weasels to voles.

Several lines of evidence suggest that our weasel capture rate reflected a biologically plausible numerical response. First, we had no evidence of a marked sexratio bias in captured weasels. Second, we found evidence for a significant interaction between season and previous vole abundance ( $t-4$ months), which was indicative of a breeding response of weasels during March-July to abundant voles in March (see Table 1, Fig. 5). This period coincides with the described peak reproduction time in Spain (Blanco 1998, Palazón 2017) and elsewhere (King and Powell 2007). Considering parameter estimates for the association between weasel capture rate and current or previous vole abundances (Table 1), the steepest slope was found between weasel capture rate in July and vole abundance in the previous March $(+0.227)$, which was twice that found between weasel capture rate in March and vole abundance in the previous November $(+0.122)$ or between weasel capture rate and current vole abundance $(+0.108)$. Weasel capture rate in July markedly increased with vole abundance in the previous March, consistent with the emergence of juveniles from the main peak in reproduction at that time. Previous vole abundances had a much weaker influence on weasel capture rate during other months (November and March), when any numerical response would be more likely to reflect immigration rather than in situ reproduction. A plausible explanation for the observed capture-rate patterns is therefore related to the seasonal reproduction of weasels.

Our weasel capture rates during vole peaks were remarkably high (1.5-2 captures/100 traps/24 h) and amongst the highest recorded (Jedrzejewski et al. 1995, King and Powell 2007). These can be explained by the very high densities of voles recorded during outbreaks in our study sites (up to $45-65$ voles/100 traps/24 h), which were higher than those recorded during vole peaks elsewhere (15-30 and 10-25 voles/100 traps/24 $\mathrm{h}$ in western France and Fennoscandia, respectively; Henttonen et al. 1987, Krebs 2013, Barraquand et al. 2014). Such comparisons, however, should be viewed with caution because of differences among studies in the type and placement of traps.
A rapid numerical response of weasels is consistent with their known ability to respond quickly to prey increases through reproduction. Unlike stoats, weasels do not have delayed implantation and can produce two litters per year, allowing for rapid population growth through reproduction (King and Powell 2007). Yet, the evidence from Fennoscandia is not consistent with this prediction (Sundell et al. 2013). In common and least weasels, direct implantation allows the fertilized zygote to develop without a pause. Rearing takes at least 9 weeks, so one full breeding cycle takes 3-4 months, allowing weasels to produce two litters per breeding season. Although evidence on the phenology of reproduction is lacking from Spain, pregnancies are usually observed from March to August further north in Europe, with first litters being born in April (King and Powell 2007). When mice or voles are numerous, well-fed adult female weasels may come into estrus again when their first litter of the year has been weaned (May). Second litters are typically born in July or August. In exceptionally good years some older females may still be suckling in October, while the earliest-born young females of the season produce their first litter in the year of their own birth (King 1980, McDonald and Harris 2002). Weasels can therefore quickly respond to high vole abundances. However, when rodents are scarce, the weasels' chances of successful reproduction are reduced, even when other food is available (Sundell 2003). The evidence gathered from NW Spain suggests that reproduction takes place all year round (pregnant and lactating females were observed in March, July, and November), but with a peak breeding season in MarchJuly (when $37 \%$ of captured females were reproducing and weasel PGR was greatest; Fig. 6). In November, young weasels were also frequently captured, and weasel captures typically declined between November and March. More detailed information (and a larger sample size) would be needed on weasel reproduction, but we suggest that when vole abundance is high in March and increases between March and July, weasels could reproduce earlier and over a longer period.

Our trapping results did not reveal a lagged numerical response of weasels to voles beyond 4 months, the shortest resolution of time yielded by our sampling schedule. When vole abundance peaked in summer of year $t$, there was no carry-over effect to the next year: weasel abundance did not peak in either spring or summer of year $t+1$. This is inconsistent with classical weasel-vole cycle models with a $\geq 1$-yr time lag emerging from plausible mechanistic assumptions. We know of no model with different assumptions suggesting that a seasonal time lag of 4 months could produce weasel-vole cycles. Furthermore, general theory of trophic interactions suggests that the emergence of 3-4-yr cycles requires a lag in the order of 9-12 months between predator and prey populations (May 1973, 1981).

Considering weasel population growth rate, we found broadly similar results: a strong positive association 
between the weasel and the common-vole PGRs during the same time intervals, no association with the PGRs of other prey (mice, shrew), and no association with previous PGRs of voles or other prey. This lack of delay in the PGR of weasels to changes in vole abundance is consistent with observations elsewhere, in the United Kingdom (Lambin and Graham 2003) or Poland (Zub et al. 2008), and challenges the generality of the specialist predator hypothesis for vole cycles. Explanations for a quick response of weasels to changes in vole abundance invoke the influence of generalist predation in terms of predation risk for both voles and weasels (Korpimaki and Norrdahl 1989, Lambin 2017) or weasel mobility and its ability to track asynchronous prey abundance fluctuations and switch to alternative prey.

\section{Weasel mobility, prey asynchrony, and diet shifts}

A spatial asynchrony in the preferred prey or a temporal asynchrony among alternative prey can both have a stabilizing influence on the predator-prey dynamics, allowing weasels to avoid starvation (Lambin 2017). In NW Spain, we found evidence for marked intraspecific synchrony among study populations of common voles 55-80 km apart (Table 2), but a lack of interspecific synchrony between weasel prey species within localities. Additionally, large-scale regional vole outbreaks are reported to last over $2 \mathrm{yr}$, affecting different provinces at different times (Luque-Larena et al. 2013). This indicates some degree of spatial asynchrony in vole cycles at a larger spatial scale. This should be confirmed in future studies, but could allow weasels to move from areas with little to no voles to areas with voles, where they may escape starvation (see Oksanen et al. 2001, Brandt and Lambin 2007, Lambin 2017). By virtue of their larger size, common weasels have a broader dietary spectrum than least weasels, and their reliance on voles is more similar to that of northern stoats (Goszczynski 1999, McDonald et al. 2000, Elmeros 2006, Brandt and Lambin 2007). In the British farmlands, the wood mouse is frequently preyed upon by weasels, which they hunt in field margins (Macdonald et al. 2004, King and Powell 2007). In the Iberian Peninsula, the diet of common weasels appears to be varied, though the relatively larger size allows for a broader diet spectrum, including small reptiles, birds, and even rabbits (Blanco 1998, Palazón 2017). Common weasels can thus switch to alternative prey (e.g., mice) when voles are scarce. Asynchrony among alternative prey means that weasels could fail to reproduce when voles are scarce though are able avoid starvation by switching prey (Erlinge 1974, Erlinge et al. 1984).

In conclusion, our empirical study evidenced that vole and weasel abundance fluctuations in NW Spain fit a 3yr population cycle. We showed that common weasels exhibited a rapid numerical response to changes in common-vole abundance, with no carryover effect from one year to the next. This result is inconsistent with classical formulations of the specialist-predator hypothesis as an explanation for the vole cycles, which invokes a 1-yr time lag in the numerical response of weasels to voles. Modeling work should explore under what circumstances delayed density dependence with a 4-month time lag in the numerical response of weasels to voles could destabilize the prey populations, or if weasel predation on voles could be overcompensatory (Lidicker 1978, Barraquand et al. 2014). More generally, our results indicate that the reliance of a specialized predator on a functional group of prey, such as small mammals, does not necessarily lead to a 1-yr delay in its numerical response, even if it can contribute to the depletion of one prey species. We suggest that spatial and inter-specific synchrony in prey dynamics are key determinants of the numerical response of predators in different ecosystems.

\section{AcKNowledgments}

This work was funded through the projects ECOCYCLES (BIODIVERSA 2008, Era-net European project, EUI200803641 and EUI2008-03658), ECOVOLE (CGL2012-35348), and ECOTULA (CGL2015-66962-C2-1-R; Ministerio de Economía y Competitividad of Spain), and by NERC NE/G002045/ 1 to XL. We thank the many people that help during fieldwork, and Deon Roos and Sally Bach for correcting the English. We held all necessary permits for animal experimentation for Spain and small-mammal capture.

\section{Literature Cited}

Barraquand, F., A. Pinot, N. G. Yoccoz, and V. Bretagnolle. 2014. Overcompensation and phase effects in a cyclic common vole population: between first and second-order cycles. Journal of Animal Ecology 83:1367-1378.

Bjørnstad, O. N., W. Falck, and N. C. Stenseth. 1995. A geographic gradient in small rodent density fluctuations: a statistical modelling approach. Proceedings of the Royal Society B 262:127-133.

Blanco, J. C. 1998. Mammíferos de España I \& II. Planeta, Barcelona, Spain.

Boutin, S. 1995. Testing predator-prey theory by studying fluctuating populations of small mammals. Wildlife Research 22:89-100.

Brandt, M. J., and X. Lambin. 2007. Movement patterns of a specialist predator, the weasel Mustela nivalis exploiting asynchronous cyclic field vole Microtus agrestis populations. Acta Theriologica 52:13-25.

Elmeros, M. 2006. Food habits of stoats Mustela erminea and weasels Mustela nivalis in Denmark. Acta Theriologica 51:179-186

Erlinge, S. 1974. Distribution, territoriality and numbers of weasels Mustela nivalis in relation to prey abundance. Oikos 25:308-314.

Erlinge, S., G. Goransson, G. Hogstedt, G. Jansson, O. Liberg, J. Loman, I. N. Nilsson, T. Vonshantz, and M. Sylven. 1984. Can vertebrate predators regulate their prey? American Naturalist 123:125-133.

Fuller, A. K., C. S. Sutherland, J. A. Royle, and M. P. Hare. 2016. Estimating population density and connectivity of American mink using spatial capture-recapture. Ecological Applications 26:1125-1135.

Gilg, O., I. Hanski, and B. Sittler. 2003. Cyclic dynamics in a simple vertebrate predator-prey community. Science 302: 866-868. 
Gorman, M. L. 1984. The response of prey to stoat (Mustela erminea) scent. Journal of Zoology 202:419-423.

Goszczynski, J. 1999. Food composition of weasels (Mustela nivalis) in Poland. Mammalia 63:431-436.

Graham, I. M. 2002. Estimating weasel Mustela nivalis abundance from tunnel tracking indices at fluctuating field vole Microtus agrestis density. Wildlife Biology 8:279-287.

Graham, I. M., and X. Lambin. 2002. The impact of weasel predation on cyclic field-vole survival: the specialist predator hypothesis contradicted. Journal of Animal Ecology 71:946956.

Hansen, T. F., N. C. Stenseth, and H. Henttonen. 1999. Multiannual vole cycles and population regulation during long winters: An analysis of seasonal density dependence. American Naturalist 154:129-139.

Hanski, I., H. Henttonen, E. Korpimaki, L. Oksanen, and P. Turchin. 2001. Small-rodent dynamics and predation. Ecology 82:1505-1520.

Hanski, I., P. Turchin, E. Korpimaki, and H. Henttonen. 1993. Population oscillations of boreal rodents-regulation by mustelid predators leads to chaos. Nature 364:232-235.

Hansson, L., and H. Henttonen. 1985. Gradients in density variations of small rodents - the importance of latitude and snow cover. Oecologia 67:394-402.

Henttonen, H., O. Gilg, R. A. Ims, E. Korpimaki, and N. G. Yoccoz. 2017. Ilkka Hanski and small mammals: from shrew metapopulations to vole and lemming cycles. Annales Zoologici Fennici 54:153-162.

Henttonen, H., T. Oksanen, A. Jortikka, and V. Haukisalmi. 1987. How much do weasels shape microtine cycles in the northern Fennoscandian taiga? Oikos 50:353-365.

Hopkins, H. L., and M. L. Kennedy. 2004. An assessment of indices of relative and absolute abundance for monitoring populations of small mammals. Wilson Society Bulletin 32:1289-1296.

Jareño, D., J. Viñuela, J. J. Luque-Larena, L. Arroyo, B. Arroyo, and F. Mougeot. 2015. Factors associated with the colonization of agricultural areas by common voles Microtus arvalis in NW Spain. Biological Invasions 17:2315-2327.

Jedrzejewska, B., and W. Jedrzejewski. 1989. Seasonal surplus killing as hunting strategy of the weasel Mustela nivalis-test of a hypothesis. Acta Theriologica 34:347-359.

Jedrzejewski, W., and B. Jedrzejewska. 1996. Rodent cycles in relation to biomass and productivity of ground vegetation and predation in the Palearctic. Acta Theriologica 41:1-34.

Jedrzejewski, W., B. Jedrzejewska, and L. Szymura. 1995. Weasel population response, home-range, and predation on rodents in a deciduous forest in Poland. Ecology 76:179-195.

Jedrzejewski, W., B. Jedrzejewska, K. Zub, and W. K. Nowakowski. 2000. Activity patterns of radio-tracked weasels Mustela nivalis in Bialowieza National Park (E Poland). Annales Zoologici Fennici 37:161-168.

King, C. M. 1980. Weasel Mustela nivalis and its prey in an English woodland. Journal of Animal Ecology 49:127-159.

King, C. M., and R. A. Powell. 2007. The natural history of weasels and stoats. Ecology, behaviour and management. Oxford University Press, Oxford, UK.

Klemola, T., M. Koivula, E. Korpimaki, and K. Norrdahl. 1997. Small mustelid predation slows population growth of Microtus voles: A predator reduction experiment. Journal of Animal Ecology 66:607-614.

Klemola, T., M. Koivula, E. Korpimaki, and K. Norrdahl. 2000. Experimental tests of predation and food hypotheses for population cycles of voles. Proceedings of the Royal Society B 267:351-356.

Korpela, K., P. Helle, H. Henttonen, E. Korpimaeki, E. Koskela, O. Ovaskainen, H. Pietiaeinen, J. Sundell, J. Valkama, and O. Huitu. 2014. Predator-vole interactions in northern Europe: the role of small mustelids revised. Proceedings of the Royal Society B 281:20142119.

Korpimaki, E., and C. J. Krebs. 1996. Predation and population cycles of small mammals-A reassessment of the predation hypothesis. BioScience 46:754-764.

Korpimaki, E., and K. Norrdahl. 1989. Avian predation on Mustelids in Europe. 1. Occurrence and effects on body size variation and life traits. Oikos 55:205-215.

Korpimaki, E., and K. Norrdahl. 1998. Experimental reduction of predators reverses the crash phase of small-rodent cycles. Ecology 79:2448-2455.

Korpimaki, E., K. Norrdahl, and J. Valkama. 1994. Reproductive investment under fluctuating predation risk-microtine rodents and small mustelids. Evolutionary Ecology 8:357368.

Korpimaki, E., L. Oksanen, T. Oksanen, T. Klemola, K. Norrdahl, and P. B. Banks. 2005. Vole cycles and predation in temperate and boreal zones of Europe. Journal of Animal Ecology 74:1150-1159.

Krebs, C. J. 2013. Population fluctuations in rodents. The University of Chicago Press, Chicago, Illinois, USA.

Krebs, C. J., R. Boonstra, and S. Boutin. 2017. Using experimentation to understand the 10-year snowshoe hare cycle in the boreal forest of North America. Journal of Animal Ecology $87: 87-100$.

Lambin, X. 2017. The population dynamics of bite-sized predators: prey dependence, territoriality, and mobility. Pages 13157 in D. W. Macdonald, C. Newman, and L. A. Harrington, editors. Biology and conservation of musteloids. University Press, Oxford, UK.

Lambin, X., V. Bretagnolle, and N. G. Yoccoz. 2006. Vole population cycles in northern and southern Europe: Is there a need for different explanations for single pattern? Journal of Animal Ecology 75:340-349.

Lambin, X., and I. M. Graham. 2003. Testing the specialist predator hypothesis for vole cycles. Trends in Ecology \& Evolution 18:493.

Lambin, X., S. J. Petty, and J. L. MacKinnon. 2000. Cyclic dynamics in field vole populations and generalist predation. Journal of Animal Ecology 69:106-118.

Lidicker, W. Z. 1978. Regulation of numbers in small mammal populations-historical reflections and a synthesis. Special Publications Pymatuning Laboratory of Ecology 5:122-141.

Luque-Larena, J. J., F. Mougeot, J. Viñuela, D. Jareño, L. Arroyo, X. Lambin, and B. Arroyo. 2013. Recent large-scale range expansion and outbreaks of the common vole (Microtus arvalis) in NW Spain. Basic and Applied Ecology 14:432-441.

Luque-Larena, J. J., F. Mougeot, B. Arroyo, and X. Lambin. 2018. Got rats? Global environmental costs of thirst for milk include acute biodiversity impacts linked to dairy feed production. Global Change Biology 24:2752-2754.

Luque-Larena, J. J., F. Mougeot, D. V. Roig, X. Lambin, R. Rodríguez-Pastor, E. Rodriguez-Valin, P. Anda, and R. Escudero. 2015. Tularemia outbreaks and common vole (Microtus arvalis) irruptive population dynamics in northwestern Spain, 1997-2014. Vector-Borne and Zoonotic Diseases 15:568-570.

Macdonald, D. W., T. E. Tew, and I. A. Todd. 2004. The ecology of weasels (Mustela nivalis) on mixed farmland in southern England. Biologia 59:235-241.

Macdonald, D. W., C. Newman, and L. A. Harrington. 2017. Biology and conservation of musteloids. Oxford University Press, Oxford, UK.

May, R. M. 1973. Time-delay versus stability in population models with two and three trophic levels. Ecology 54:315325. 
May, R. M. 1981. Models for single populations. Pages 5-77 in R. M. May, editor. Theoretical ecology. Principles and applications. Second edition. Blackwell Scientific, Oxford, UK

McDonald, R. A., and S. Harris. 2002. Population biology of stoats Mustela erminea and weasels Mustela nivalis on game estates in Great Britain. Journal of Applied Ecology 39:793-805.

McDonald, R. A., C. Webbon, and S. Harris. 2000. The diet of stoats (Mustela erminea) and weasels (Mustela nivalis) in Great Britain. Journal of Zoology 252:363-371.

Myers, J. H. 2018. Population cycles: generalities, exceptions and remaining mysteries. Proceedings of the Royal Society B 285:20172841.

Oksanen, T., L. Oksanen, M. Schneider, and M. Aunapuu. 2001. Regulation, cycles and stability in northern carnivoreherbivore systems: back to first principles. Oikos 94:101-117.

Palazón, S. 2017. Comadreja-Mustela nivalis (Linnaeus, 1761). In A. Salvador and I. Barja, editors. Enciclopedia Virtual de los Vertebrados Españoles. Museo Nacional de Ciencias Naturales, Madrid, Spain. http://www.vertebradosiberic os.org/

Paz, A., D. Jareño, L. Arroyo, J. Vinuela, B. Arroyo, F. Mougeot, J. Jose Luque-Larena, and J. Antonio Fargallo. 2013. Avian predators as a biological control system of common vole (Microtus arvalis) populations in north-western Spain: experimental set-up and preliminary results. Pest Management Science 69:444-450.

R Core Team. 2014. R: A language and environment for statistical computing. R Foundation for Statistical Computing, Vienna, Austria. www.r-project.org

Rodríguez-Pastor, R., J. J. Luque-Larena, X. Lambin, and F. Mougeot. 2016. "Living on the edge": The role of field margins for common vole (Microtus arvalis) populations in recently colonised Mediterranean farmland. Agriculture Ecosystems \& Environment 231:206-217.

Romairone, J., J. Jimenez, J. J. Luque-Larena, and F. Mougeot. 2018. Spatial capture-recapture design and modelling for the study of small mammals. PLoS ONE 13:e0198766.

Sundell, J. 2003. Reproduction of the least weasel in captivity: basic observations and the influence of food availability. Acta Theriologica 48:59-72.

Sundell, J., R. B. O'Hara, P. Helle, P. Hellstedt, H. Henttonen, and H. Pietiainen. 2013. Numerical response of small mustelids to vole abundance: delayed or not? Oikos 122:1112-1120.

Terraube, J., B. Arroyo, M. Madders, and F. Mougeot. 2011. Diet specialisation and foraging efficiency under fluctuating food abundance in sympatric avian predators. Oikos 120:234 244

Tkadlec, E., and N. C. Stenseth. 2001. A new geographical gradient in vole population dynamics. Proceedings of the Royal Society B 268:1547-1552.

Turchin, P. 2003. Complex population dynamics. A theoretical/ empirical synthesis. University Press, Princeton, New Jersey, USA.

Turchin, P., and I. Hanski. 1997. An empirically based model for latitudinal gradient in vole population dynamics. American Naturalist 149:842-874.

Turchin, P., and I. Hanski. 2001. Contrasting alternative hypotheses about rodent cycles by translating them into parameterized models. Ecology Letters 4:267-276.

Zub, K., L. Soennichsen, and P. A. Szafranska. 2008. Habitat requirements of weasels Mustela nivalis constrain their impact on prey populations in complex ecosystems of the temperate zone. Oecologia 157:571-582.

\section{SUPPORTING INFORMATION}

Additional supporting information may be found in the online version of this article at http://onlinelibrary.wiley.com/doi/ 10.1002/ecy.2776/suppinfo 